\title{
The Effect of Admission Serum Magnesium on the Acute Kidney Injury Among Patients with Malignancy
}

This article was published in the following Dove Press journal:

Cancer Management and Research

\author{
Daoqi Shen \\ Yimei Wang \\ Jiarui $\mathrm{Xu}$ \\ Yang Li \\ Xiaohong Chen \\ Man Guo \\ Xuemei Geng \\ Xiaoqiang Ding \\ Xialian Xu
}

Department of Nephrology, Zhongshan Hospital, Fudan University, Shanghai Institute of Kidney Disease and Dialysis (SIKD), Shanghai Key Laboratory of

Kidney and Blood Purification, Shanghai Medical Center of Kidney Disease, Shanghai, People's Republic of China
Correspondence: Xiaoqiang Ding; Xialian Xu

Department of Nephrology, Zhongshan Hospital, Fudan University, Shanghai Institute of Kidney Disease and Dialysis (SIKD), Shanghai Key Laboratory of Kidney and Blood Purification, Shanghai Medical Center of Kidney Disease, 180 Fenglin Road, Xuhui District, Shanghai, People's Republic of China

Email ding.xiaoqiang@zs-hospital.sh.cn; xu.xialian@zs-hospital.sh.cn
Purpose: This study aimed to explore the relationship between serum magnesium $(\mathrm{Mg})$ levels and incidence of acute kidney injury (AKI) in patients with malignancy.

Patients and Methods: Hospitalized patients with malignancy between October 1, 2014 and September 30, 2015 in Zhongshan Hospital were recruited. All relevant data were extracted from the electronic database.

Results: All 99,845 patients were enrolled and 16,082 eligible patients were divided into three groups according to admission serum $\mathrm{Mg}$ levels in this study. Among them, 2383 $(14.8 \%)$ cases were diagnosed as AKI. The incidence of AKI showed a V trend with the increase of serum $\mathrm{Mg}$ level. The effect of low serum $\mathrm{Mg}$ level on the onset of AKI seems to be greater than high serum $\mathrm{Mg}$ level. Patients with low serum $\mathrm{Mg}$ level spent a longer time in the hospital than those with normal serum $\mathrm{Mg}$ level and high serum $\mathrm{Mg}$ level. Further, multivariate logistic regression model was used to assess the importance of serum $\mathrm{Mg}$ level to influence AKI incidence. There was a higher AKI incidence in patients with magnesium level $0.66 \mathrm{mmol} / \mathrm{L}$ or less $(\mathrm{aOR}=2.438,95 \% \mathrm{CI}=1.696,3.505)$.

Conclusion: Low serum $\mathrm{Mg}$ level might be a independent risk factor for AKI in patients with malignancy. Appropriate clinical intervention for serum $\mathrm{Mg}$ disorder may contribute to decreasing the incidence of AKI and the possibility of poor outcomes in cancer patients.

Keywords: hypomagnesemia, cancer, acute kidney injury, electrolyte disorders

\section{Introduction}

Magnesium (Mg), one of the indispensable mineral elements in the human body, is the second most important cation in human cells. It plays a crucial role in catalyzing biochemical and physiological reactions, including activating a variety of enzymes in the body, ${ }^{1}$ regulating nerve functions, ${ }^{2}$ maintaining the stability of nucleic acid structure, ${ }^{3}$ participating in protein synthesis and ribosome modulation. ${ }^{4}$ Dysmagnesemia not only interferes with various physiology activities, but also results in the progression of the diseases including renal dysfunction.

Acute kidney injury (AKI) is an important factor affecting the prognosis of patients with cancer, ${ }^{5-7}$ which greatly related to morbidity and mortality. ${ }^{8}$ The risk of AKI among cancer patients was significantly higher than that of patients without malignancy. ${ }^{9}$ The use of chemotherapeutic drugs, radiotherapy, surgery, urinary tract obstruction, malignant infiltration, and tumor lysis syndrome contribute to the incidence of AKI. ${ }^{6,10}$ Electrolyte disorders are very common in patients with malignant tumors. $^{11,12}$ However, few studies have looked at disorders of serum $\mathrm{Mg}$ in cancer patients. Thus, the purpose of our study was to explore the effect of serum $\mathrm{Mg}$ on the incidence of HA-AKI and the prognosis of patients with malignant tumors. 


\section{Patients and Methods}

This study was approved by the institutional clinical research Ethics Review Board (Ethics Committee of Zhongshan Hospital, Fudan University), which accordance with the Declaration of Helsinki. The Informed consent from individuals was waived because patients' identification information were anonymous for privacy.

\section{Study Population and Data Collection}

The total number of patients admitted to Zhongshan hospital, Shanghai on September 30, 2015 was 99,845. After excluding 211 patients under 14 years old, 4,340 who had been hospitalized for less than 24 hours, 10,539 patients of less than twice creatinine measurements, 1638 patients from chronic kidney disease stage 5 to dialysis, 56,250 patients without malignancy. Of the remaining 26,867 admissions, 16,082 (59.9\%) cases had magnesium measurement. For patients with multiple admissions during this period, we treated each admission as a separate case (Figure 1). All relevant data were collected from the hospital electronic information database and the laboratory database. Clinical characteristics and demographics included age, sex, length of hospital stay, hospitalization costs, and so on. Laboratory indicators were composed of white blood cell count (WBC), hemoglobin (HGB), serum creatinine ( $\mathrm{sCr}$ ), albumin (ALB), uric acid (UA), electrolytes (sodium $\mathrm{Na}$, potassium $\mathrm{K}$, chloride $\mathrm{Cl}$, calcium $\mathrm{Ca}$, phosphorus P).

\section{Definition of AKI and Dysmagnesemia}

AKI was diagnosed using KDIGO criteria: ${ }^{13} \mathrm{sCr}$ increased $\geq 26.5 \mu \mathrm{mol} / \mathrm{L}(0.3 \mathrm{mg} / \mathrm{dL})$ within $48 \mathrm{~h}$ or $\mathrm{sCr} \geq 1.5$ times of baseline value, and the above situation was confirmed or speculated to occur within 7 days. AKI stages were defined as Stage 1: $\mathrm{sCr}$ increase $\geq 0.3 \mathrm{mg} / \mathrm{dL}$ or $\mathrm{sCr} \geq 1.5-1.9$ times of baseline; Stage 2: sCr increase $\geq 2$.9-3.0 times of baseline; and Stage 3: $\mathrm{sCr}$ increase $\geq 4.0 \mathrm{mg} / \mathrm{dL}, \mathrm{sCr} \geq 3.0$ times of baseline or initiation of renal replacement therapy. Communityacquired (CA) AKI was defined as the following criteria: ${ }^{14}$ (1) AKI was diagnosed on admission; (2) $\mathrm{sCr}$ changes on

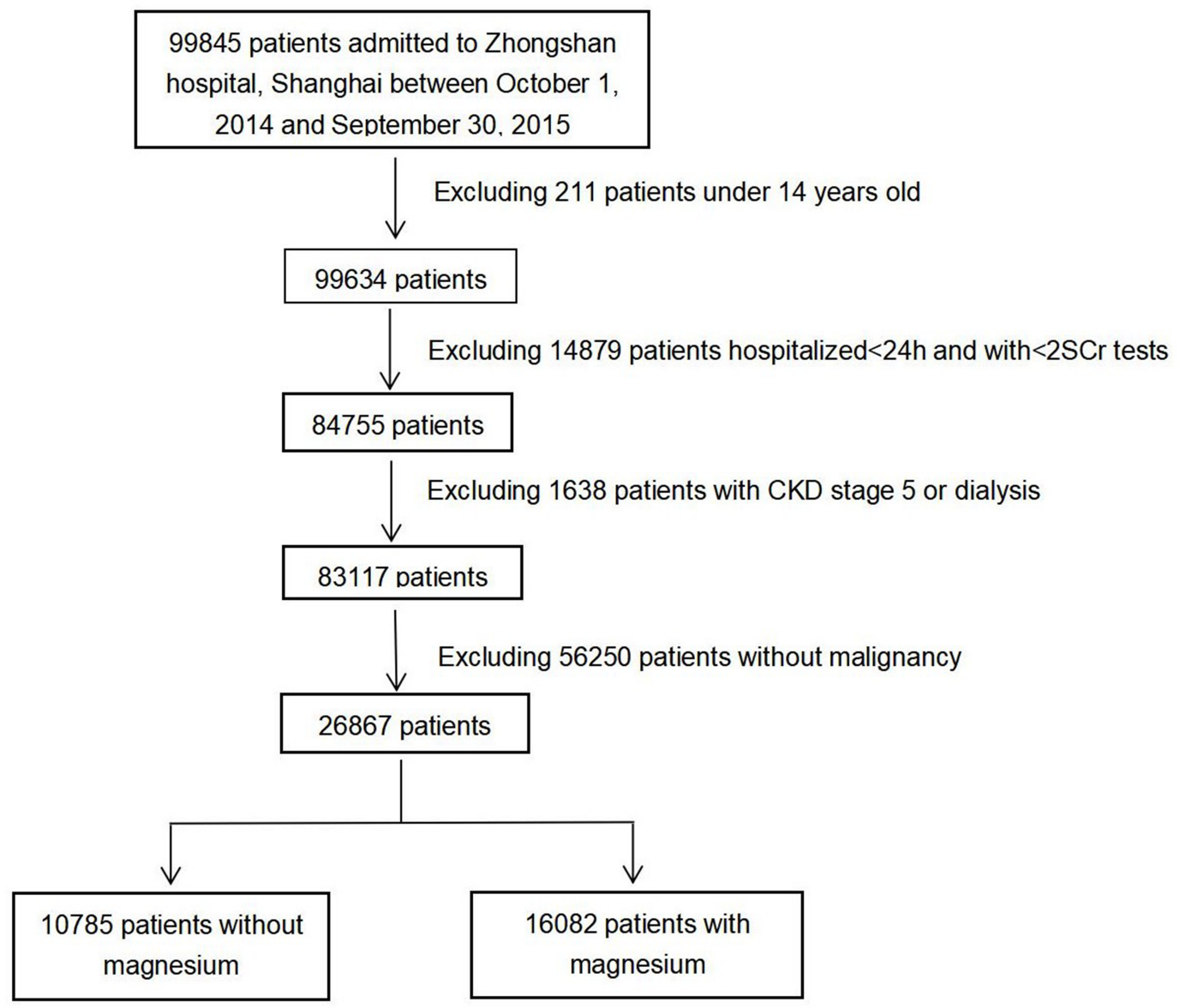

Figure I Flow chart of the study. 
the first day of admission were consistent with the KDIGO definition. (3) $\mathrm{sCr}$ at admission exceeds 1.5 times the minimum SCr during hospitalization (assumed as baseline). Patients with AKI but not meeting CA-AKI criteria were identified as hospital acquired (HA) AKI. ${ }^{14}$

The normal range of serum $\mathrm{Mg}$ in our hospital is $0.67-1.04 \mathrm{mmol} / \mathrm{L}$, serum $\mathrm{Mg} \leq 0.66 \mathrm{mmol} / \mathrm{L}$ was defined as hypomagnesemia while serum $\mathrm{Mg} \geq 1.05 \mathrm{mmol} / \mathrm{L}$ was defined as hypermagnesemia. Adjusted-Mg were magnesium levels after adjusting for albumin levels. ${ }^{15}$

\section{Statistical Analysis}

Statistical Package for the Social Sciences (SPSS), version 26.0 was applied. Variables' distribution was analyzed with the Kolmogorov-Smirnov test. Continuous data were represented by the medians with interquartile ranges (IQRs), while categorical variables were shown in frequency (n) and percentage (\%). Based on the number of groups, Mann-Whitney test or Kruskal-Wallis test with Bonferroni was used for group comparisons. Chi-squared test and Fisher exact test were performed to analyze categorical variables. Univariate analysis was employed individually and variables with $\mathrm{P}<0.15$ were selected into the multiple logistic regression model. In the multiple logistic regression model, we adjusted the cofounding factors. Odds ratios (OR) with 95\% confidence interval (CI) were presented to show the relationship between admission $\mathrm{Mg}$ and AKI. P-value $<0.05$ was considered statistically significant.

\section{Results}

\section{Epidemiological results}

Of the remaining 16,082 hospitalized cancer patients, there were 10,388 (65.4\%) male cases and 5694 (35.4\%) female cases, the baseline median age of the patients was $61(51,68)$ years. There were $2374(14.8 \%)$ cases with hypertension, $1209(7.5 \%)$ cases with diabetes, 333 (2.1\%) cases with coronary heart disease, $177(1.1 \%)$ cases with stroke, and $52(0.3 \%)$ cases with heart failure (Supplementary Table 1$)$. Dysmagnesemia accounted for $8.2 \%$ of all hospitalized patients. The distribution of $\mathrm{Mg}$ levels was as follows: less than $0.66 \mathrm{mmol} / \mathrm{L}, 165(1.0 \%)$ patients; $0.67-1.04 \mathrm{mmol} / \mathrm{L}$, $14,770(91.8 \%)$ patients; and $1.05 \mathrm{mmol} / \mathrm{L}$ or higher, 1147 $(7.1 \%)$ patients.

The distribution of various tumors based on admission serum $\mathrm{Mg}$ levels is shown in Figure 2. The top three tumor types were respiratory, gastrointestinal, and gynecological tumors in the patients with hypomagnesemia, which were always treated by platinum-based chemotherapy drugs. The distributions of gynecological cancer, bone tumor, and soft tissue tumor changed dramatically from normal $\mathrm{Mg}$ levels to low Mg levels. Compared with hypomagnesemia, hypermagnesemia was more common in patient with gastrointestinal and liver/gallbladder cancer.

\section{Clinical Features of Patients with AKI or Non-AKI}

We compared baseline characteristics and complications in patients categorized by AKI (Table 1). In total 16,082 patients with malignancy, 2383 (14.8\%) patients were diagnosed with AKI. Among them CA-AKI compromised 564 (3.5\%) cases and HA-AKI compromised 1989 (11.3\%) cases. According to statistical calculation, AKI group and non-AKI group had marked differences in age, sex, ALB, WBC, HGB, serum electrolytes, sCr, UA, and complications (hypertension, diabetes mellitus, stroke, heart failure). In contrast to those without AKI, AKI patients had higher median age and $\mathrm{WBC}$, at the same time, lower ALB and HGB.

Among the patients with AKI, the disorder of serum $\mathrm{Mg}$ accounted for $11.8 \%$, while the disorder of serum $\mathrm{Mg}$ in non-AKI patients was only $7.5 \%$. AKI patients had lower serum $\mathrm{Mg}$ levels in contrast to those without AKI. There was a significant difference in mortality between AKI patients and non-AKI patients $(\mathrm{P}<0.001)$.

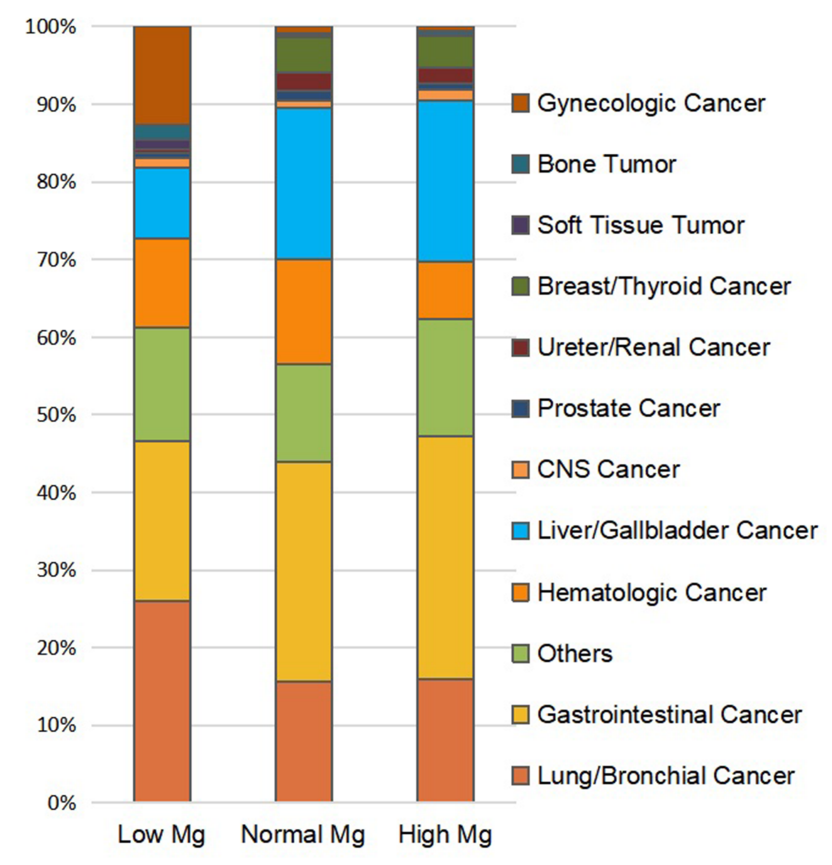

Figure 2 The proportion of various tumors based on admission serum $\mathrm{Mg}$ levels. 
Table I Demographic, Clinical, and Biochemical Data of the Patients

\begin{tabular}{|c|c|c|c|c|}
\hline Item & $\begin{array}{l}\text { CA-AKI } \\
N=564(3.5)\end{array}$ & $\begin{array}{l}\text { HA-AKI } \\
N=1989(\mid 1.3)\end{array}$ & $\begin{array}{l}\text { Non-AKI } \\
N=13,699(85.2)\end{array}$ & P-value \\
\hline $\begin{array}{l}\text { Age }[M(P 25, P 75), y e a r s] \\
\text { Male[n(\%)] }\end{array}$ & $\begin{array}{l}64(57,73) \\
382(67.7)\end{array}$ & $\begin{array}{l}62(53,69)^{*} \\
1236(62.1)\end{array}$ & $\begin{array}{l}60(51,67)^{* \#} \\
8770(64.0)^{\#}\end{array}$ & $\begin{array}{l}<0.001 \\
0.001\end{array}$ \\
\hline $\begin{array}{l}\text { Laboratory tests } \\
\text { ALB }[M(P 25, P 75), g / L] \\
\text { WBC }\left[M(P 25, P 75), \times 10^{9} / \mathrm{L}\right] \\
\mathrm{HGB}[\mathrm{M}(\mathrm{P} 25, \mathrm{P} 75), \mathrm{g} / \mathrm{L}] \\
\mathrm{Na}[\mathrm{M}(\mathrm{P} 25, \mathrm{P} 75), \mathrm{mmol} / \mathrm{L}] \\
\mathrm{K}[\mathrm{M}(\mathrm{P} 25, \mathrm{P} 75), \mathrm{mmol} / \mathrm{L}] \\
\mathrm{Cl}[\mathrm{M}(\mathrm{P} 25, \mathrm{P} 75), \mathrm{mmol} / \mathrm{L}] \\
\mathrm{Ca}[\mathrm{M}(\mathrm{P} 25, \mathrm{P} 75), \mathrm{mmol} / \mathrm{L}] \\
\mathrm{Mg}[\mathrm{M}(\mathrm{P} 25, \mathrm{P} 75), \mathrm{mmol} / \mathrm{L}] \\
\mathrm{Adjusted}-\mathrm{Mg}[\mathrm{M}(\mathrm{P} 25, \mathrm{P} 75), \mathrm{mmol} / \mathrm{L}] \\
\mathrm{P}[\mathrm{M}(\mathrm{P} 25, \mathrm{P} 75), \mathrm{mmol} / \mathrm{L}] \\
\mathrm{sCr}[\mathrm{M}(\mathrm{P} 25, \mathrm{P} 75), \mu \mathrm{mol} / \mathrm{L}] \\
\mathrm{UA}[\mathrm{M}(\mathrm{P} 25, \mathrm{P} 75), \mathrm{mmol} / \mathrm{L}] \\
\text { Deaths[n(\%)] }\end{array}$ & $\begin{array}{l}37(33,40) \\
6.16(4.68,8.52) \\
113(94,128) \\
140(137,143) \\
4.1(3.8,4.5) \\
102(99,105) \\
2.28(2.15,2.38) \\
0.91(0.84,0.98) \\
0.93(0.85,1.00) \\
1.14(0.95,1.30) \\
123(82,152) \\
363(287,458) \\
37(6.5)\end{array}$ & $\begin{array}{l}39(35,41)^{*} \\
5.70(4.33,7.34)^{*} \\
121(102,136)^{*} \\
141(138,143) \\
4.1(3.8,4.3)^{*} \\
102(100,105) \\
2.29(2.19,2.39)^{*} \\
0.91(0.84,0.97) \\
0.93(0.86,0.98) \\
1.12(0.96,1.27) \\
76(62,92)^{*} \\
297(237,365)^{*} \\
89(4.8)\end{array}$ & $\begin{array}{l}39(36,42)^{* \#} \\
5.55(4.38,7.02)^{* \#} \\
124(111,137)^{* \#} \\
141(139,143)^{* \#} \\
4.0(3.8,4.3)^{* \#} \\
103(101,105)^{* \#} \\
2.31(2.22,2.39)^{* \#} \\
0.92(0.86,0.97)^{* \#} \\
0.93(0.87,0.98) \\
1.10(0.97,1.24)^{* \#} \\
69(59,81)^{* \#} \\
290(236,347)^{* \#} \\
111(0.8)^{* \#}\end{array}$ & $\begin{array}{l}<0.001 \\
<0.001 \\
<0.001 \\
<0.001 \\
<0.001 \\
<0.001 \\
<0.001 \\
0.006 \\
0.104 \\
0.023 \\
<0.001 \\
<0.001 \\
<0.001\end{array}$ \\
\hline $\begin{array}{l}\text { Comorbidities[n(\%)] } \\
\text { Hypertension[n(\%)] } \\
\text { Diabetes Mellitus[n(\%)] } \\
\text { Coronary heart disease[n(\%)] } \\
\text { Stroke[n(\%)] } \\
\text { Heart failure[n(\%)] }\end{array}$ & $\begin{array}{l}160(28.4) \\
83(14.7) \\
17(3.0) \\
13(2.3) \\
12(2.1)\end{array}$ & $\begin{array}{l}254(14.0)^{*} \\
159(8.7)^{*} \\
32(1.8) \\
28(1.5) \\
12(0.7)^{*}\end{array}$ & $\begin{array}{l}1960(14.3)^{*} \\
967(7.1)^{* \#} \\
284(2.1) \\
136(1.0)^{*} \\
28(0.2)^{* \#}\end{array}$ & $\begin{array}{l}<0.001 \\
<0.001 \\
0.188 \\
0.002 \\
<0.001\end{array}$ \\
\hline
\end{tabular}

Notes: *P<0.05 vs CA-AKI ${ }^{*} \mathrm{P}<0.05$ vs HA-AKI.

Abbreviations: ALB, albumin; WBC, white blood cell count; HGB, hemoglobin; sCr, serum creatinine; UA, uric acid.

\section{The Relationship Between Admission Serum $\mathrm{Mg}$ and Incidence of AKI}

Based on the admission Mg levels, we analyzed the incidence of AKI in patients with malignancy (Table 2). When serum $\mathrm{Mg}$ was $0.67-1.04 \mathrm{mmol} / \mathrm{L}$, the incidence of AKI was the lowest (14.2\%). The incidence of AKI in hypomagnesemia patients was significantly increased to $40 \%$. When serum $\mathrm{Mg} \geq 1.05 \mathrm{mmol} / \mathrm{L}$, the incidence of $\mathrm{AKI}$ was $18.7 \%$.

The median length of hospital stay (LOS) and total cost of the patients were 7.5 (4.0, 12.5days) and 25,918 $(11,941,45670 \mathrm{CNY})$ respectively. Patients with low $\mathrm{Mg}$ levels stayed in the hospital longer than patients with normal Mg levels and high $\mathrm{Mg}$ levels. It illustrated that the longest LOS was observed in patients with $\mathrm{Mg} \leq 0.66 \mathrm{mmol} / \mathrm{L}$ (11.5days), which were 1.5 times longer than the patients with normal Mg levels (7.5 days). There was no significant difference in total expenditure and surgery cost among the three groups. However, medicine cost in the low $\mathrm{Mg}$ group (7358 CNY) was apparently higher than the other two groups $(\mathrm{P}<0.001)$.

\section{Admission Serum Mg Levels and Risk of HA-AKI}

To explore the relationship of admission Mg status and HAAKI, we used $0.67-1.04 \mathrm{mmol} / \mathrm{L}$ as a reference to build a multivariate logistic regression model. Then we compared the odds ratios before and after the adjustment of age, sex, ALB, HGB, WBC, sCr, UA, electrolytes, complications and tumor types. As Table 3, before correcting for confounding factors, admission $\mathrm{Mg} \leq 0.66 \mathrm{mmol} / \mathrm{L}$ was independent risk factors for HA-AKI with ORs of 3.019 (95\% CI=2.135, 4.269). When adjusted for all relevant factors, admission $\mathrm{Mg} \leq 0.66 \mathrm{mmol} / \mathrm{L}$ still associated with an increased occurrence of HA-AKI $(\mathrm{aOR}=2.438,95 \% \mathrm{CI}=1.696,3.505)$.

\section{Subgroup Analysis Among Patients with Different Treatments}

Considering different treatments may affect AKI incidence, we also analyzed the relationship between $\mathrm{Mg}$ levels and HA-AKI incidence based on various treatments (Figure 3). Serum Mg levels significantly correlated with HA-AKI incidence among patients receiving surgery, 
Table 2 Clinical Outcomes of Patients with Different Serum Mg Levels

\begin{tabular}{|c|c|c|c|c|c|}
\hline & $\begin{array}{l}\text { All Patients } \\
\mathrm{N}=16,082\end{array}$ & $\begin{array}{l}\text { Low Mg } \\
\mathrm{N}=165\end{array}$ & $\begin{array}{l}\text { Normal Mg } \\
N=14,770\end{array}$ & $\begin{array}{l}\text { High Mg } \\
N=1 / 47\end{array}$ & P-value \\
\hline AKI stage [n(\%)] & & & & & $<0.001$ \\
\hline I & $2149(90.2)$ & $58(87.9)$ & $1906(90.7)$ & $185(86.0)$ & \\
\hline 2 & $182(7.6)$ & $8(12.1)$ & $157(7.5)$ & $17(7.9)$ & \\
\hline 3 & $52(2.2)$ & 0 & $39(1.9)$ & $13(6.0)$ & \\
\hline Total cost(CNY) & $25,9 \mid 8(|I, 94|, 45,607)$ & $27,18 \mid(|2,3| 3,57,293)$ & $25,953(I I, 994,45,66 I)$ & $25,213(11,334,44,232)$ & 0.799 \\
\hline Surgery cost(CNY) & $960(0,6910)$ & $480(0,7545)$ & $935(0,6910)$ & $1698(0,6885)$ & 0.346 \\
\hline Medicine cost(CNY) & $4800(2240,8990)$ & $7358(3604,15,128)$ & $4782(233 \mathrm{I}, 8936)^{*}$ & $4756(2|34,90| 8)^{*}$ & $<0.001$ \\
\hline LOS(days) & $7.5(4.0,12.5)$ & II $.5(7.0,19.5)$ & $7.5(4.0,12.5)^{*}$ & $8.0(4.0,12.5)^{*}$ & $<0.001$ \\
\hline Treatment & & & & & 0.007 \\
\hline surgery & $5590(34.8)$ & $5 \mathrm{I}(30.9)$ & $5134(34.8)$ & $405(35.3)$ & \\
\hline Chemotherapy & $6275(39.0)$ & $8 I(49.1)$ & $579 \mid(39.2)$ & $403(35.1)$ & \\
\hline Interventional therapy & $3465(21.5)$ & $25(15.2)$ & $3161(21.4)$ & $279(24.3)$ & \\
\hline Untreated & $752(4.7)$ & $8(4.8)$ & $687(4.6)$ & $60(5.2)$ & \\
\hline
\end{tabular}

Notes: ${ }^{*} \mathrm{P}<0.05 \mathrm{vs}$ low $\mathrm{Mg}{ }^{*} \mathrm{P}<0.05 \mathrm{vs}$ normal $\mathrm{Mg}$.

Abbreviation: LOS, length of hospital stay.

chemotherapy, and interventional therapy $(\mathrm{P}<0.005)$. In developing HA-AKI in surgery, chemotherapy the multivariate logistic regression analysis, low $\mathrm{Mg} \quad(\mathrm{aOR}=2.785,95 \% \mathrm{CI}=1.498,5.178 ; \mathrm{aOR}=3.608,95 \%$ level was significantly associated with increased risk of $\mathrm{CI}=2.173,5.991)$. In interventional therapy group, high

Table 3 Logistic Regression Analysis of Independent Risk Factors for HA-AKI

\begin{tabular}{|c|c|c|c|c|}
\hline & \multicolumn{2}{|c|}{ Univariate Logistic Regression } & \multicolumn{2}{|c|}{ Multivariate Logistic Regression } \\
\hline & $\mathrm{OR}(95 \% \mathrm{Cl})$ & P-value & $\mathrm{aOR}(95 \% \mathrm{Cl})$ & P-value \\
\hline Age & $1.006(1.002,1.010)$ & 0.002 & $1.00 \mathrm{I}(0.997,1.005)$ & 0.593 \\
\hline Sex & $0.845(0.761,0.937)$ & 0.001 & $0.857(0.762,0.964)$ & 0.010 \\
\hline $\mathrm{Na}$ & $0.963(0.950,0.976)$ & $<0.001$ & $1.021(0.995,1.047)$ & 0.116 \\
\hline K & I.100(0.982,I.232) & 0.100 & $1.044(0.928,1.175)$ & 0.471 \\
\hline $\mathrm{Cl}$ & $0.962(0.950,0.974)$ & $<0.001$ & $0.955(0.934,0.977)$ & $<0.001$ \\
\hline $\mathrm{Ca}$ & $0.487(0.354,0.669)$ & $<0.001$ & $0.632(0.426,0.940)$ & 0.023 \\
\hline$P$ & $1.264(1.011,1.580)$ & 0.040 & $1.509(1.182,1.926)$ & 0.001 \\
\hline ALB & $0.967(0.958,0.976)$ & $<0.001$ & $0.982(0.969,0.995)$ & 0.007 \\
\hline HGB & $0.992(0.989,0.994)$ & $<0.001$ & $0.994(0.992,0.997)$ & $<0.001$ \\
\hline WBC & $1.011(1.005,1.017)$ & $<0.001$ & $1.007(1.001,1.013)$ & 0.030 \\
\hline $\mathrm{sCr}$ & $1.001(1.000,1.001)$ & $<0.001$ & $1.003(1.001,1.005)$ & 0.004 \\
\hline UA & $0.930(0.808,1.070)$ & 0.308 & & \\
\hline Hypertension & $1.205(1.012,1.435)$ & 0.036 & $0.788(0.674,0.921)$ & 0.003 \\
\hline Diabetes & I.489(I.284,I.726) & $<0.001$ & $1.218(1.009,1.470)$ & 0.040 \\
\hline Stroke & $\mathrm{I} .48 \mathrm{I}(0.986,2.224)$ & 0.058 & I.648(I.082,2.509) & 0.020 \\
\hline Heart failure & $2.362(\mathrm{I} .237,4.5 \mathrm{II})$ & 0.009 & $1.538(0.785,3.012)$ & 0.210 \\
\hline $\mathrm{Mg} \leq 0.66 \mathrm{mmol} / \mathrm{L}$ & $3.019(2.135,4.269)$ & $<0.001$ & $2.438(1.696,3.505)$ & $<0.001$ \\
\hline $0.67<\mathrm{Mg}<1.04 \mathrm{mmol} / \mathrm{L}$ & 1 & & I & \\
\hline $\mathrm{Mg} \geq 1.05 \mathrm{mmol} / \mathrm{L}$ & I.I37(0.947,I.366) & 0.168 & I.II4(0.923,I.I.343) & 0.261 \\
\hline Thoracic tumor & I.324(I.189, I.474) & $<0.001$ & $1.325(1.116,1.572)$ & 0.001 \\
\hline Abdominal tumor & $0.897(0.814,0.990)$ & 0.030 & $0.991(0.843,1.165)$ & 0.909 \\
\hline Hematological tumor & $1.045(0.905,1.206)$ & 0.553 & & \\
\hline Other tumor & $0.733(0.624,0.861)$ & $<0.001$ & $0.830(0.672,1.026)$ & 0.084 \\
\hline
\end{tabular}

Notes: aOR was adjusted for demographic and clinical factors as age, sex, ion, ALB, HGB, WBC, sCr, comorbidities, cancer types.

Abbreviations: ALB, albumin; WBC, white blood cell count; HGB, hemoglobin; sCr, serum creatinine; UA, uric acid. 


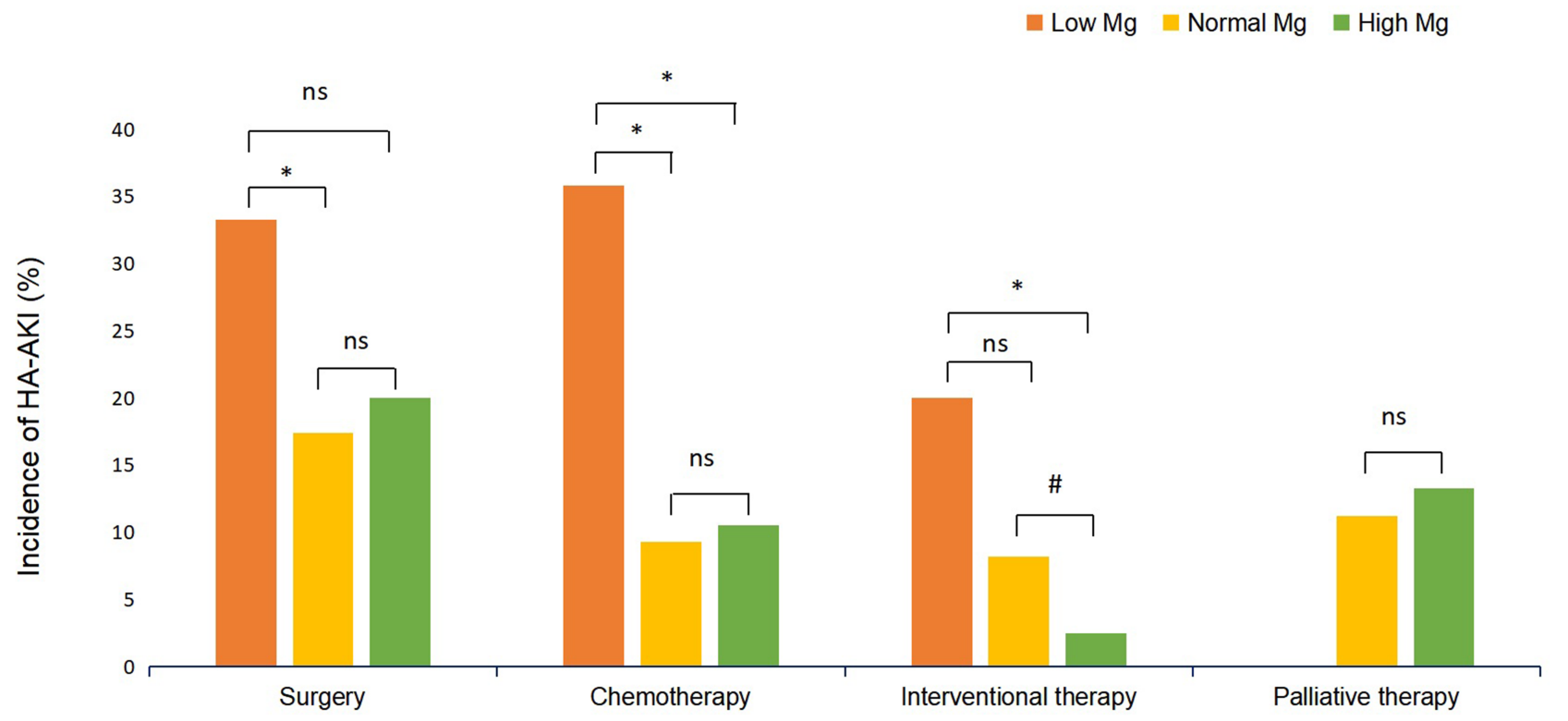

Figure $3 \mathrm{HA}-\mathrm{AKI}$ incidence among patients with different treatments. Notes: ${ }^{*} \mathrm{P}<0.05 \mathrm{vs}$ low $\mathrm{Mg}$; ${ }^{\#} \mathrm{P}<0.05 \mathrm{vs}$ normal Mg. Abbreviation: NS, no significance.

$\mathrm{Mg}$ level correlated with decreased HA-AKI incidence $(\mathrm{aOR}=0.369,95 \% \mathrm{CI}=0.170,0.804)$ (Table 4).

\section{Discussion}

Electrolyte disturbance was common in cancer patients, which was accompanied by the occurrence of AKI. In this study, we demonstrated that dysmagnesemia was related to higher AKI incidence in patients with malignancy. The incidence of AKI was lowest when serum $\mathrm{Mg}$ was normal $(0.67-1.04 \mathrm{mmol} / \mathrm{L})$. The incidence of AKI in the hypomagnesemia group was 2.8 times higher than that in the normal $\mathrm{Mg}$ group, while the hypermagnesemia group was 1.3 times higher than that in the normal $\mathrm{Mg}$ group. This is the first study assessing the association between serum $\mathrm{Mg}$ levels and AKI in patients with malignancy.

Kidney plays an irreplaceable role in maintaining the balance of magnesium by reabsorbing and excreting magnesium in the proximal tubule, the thick ascending limb of the Henry's circulation, the distal tubule. ${ }^{16}$ Because the kidney acts as an organ excreting and reabsorbing ions, electrolyte disorders may be found in kidney failure. Many researchers pay their attention to electrolytes like potassium, sodium, and calcium, however, the studies on magnesium are very few. Patients with low serum $\mathrm{Mg}$ are often companied by potassium and calcium deficiency, ${ }^{17,18}$ which obscures the lack of magnesium concentration. In this study, we analyzed the incidence of AKI and serum
$\mathrm{Mg}$ concentration in large numbers of patients with malignancy. Then we explored the association between HA-AKI and serum $\mathrm{Mg}$ concentration in patients with malignancy. Patients with dysmagnesemia presented a higher incidence of longer hospital stay and hospital mortality. In comparison with hypermagnesemia, patients with hypomagnesemia showed worse outcomes in length of stay and drug costs. Therefore, our study is the first to analyze the relationship between serum $\mathrm{Mg}$ disorders and the incidence of HA-AKI in such large-scale cancer patients.

Cancer patients are more likely to develop electrolyte disorders that can interfere with cancer treatments and bring about adverse consequences. ${ }^{19}$ Hypomagnesemia is one of the common electrolyte disorders in cancer patients, which can be explained for the following reasons. First, reduced $\mathrm{Mg}$ intake due to poor nutrition and eating disorders. Second, gastrointestinal loss of Mg results from nausea and vomiting. Third, urinary $\mathrm{Mg}$ wasting caused by chemotherapeutic drugs like carboplatin, immunosuppressive agent like cyclosporine, and molecular targeted drug like cetuximab. ${ }^{12}$ In our study, low serum $\mathrm{Mg}$ was common in patients with gynecological cancer, bone tumors, and soft tissue tumors. This may be related to the fact that platinum is one of the most common drugs in gynecological therapy. The extensive use of platinum-based chemotherapy accounted for the body magnesium deficiency due to the damage of renal tubular epithelial cells induced 
Table 4 Logistic Regression Between Serum Mg Levels and HA-AKI Based on Treatments

\begin{tabular}{|c|c|c|c|c|}
\hline & \multicolumn{2}{|c|}{ Univariate Logistic Regression } & \multicolumn{2}{|c|}{ Multivariate Logistic Regression } \\
\hline & OR(95\% Cl) & P-value & $\operatorname{aOR}(95 \% \mathrm{Cl})$ & P-value \\
\hline \multicolumn{5}{|l|}{ Surgery } \\
\hline$\leq 0.66 \mathrm{mmol} / \mathrm{L}$ & $2.378(1.322,4.275)$ & 0.004 & $2.785(1.498,5.178)$ & 0.001 \\
\hline $0.67-1.04 \mathrm{mmol} / \mathrm{L}$ & I & & I & \\
\hline$\geq 1.05 \mathrm{mmol} / \mathrm{L}$ & I.189(0.922, I.533) & 0.182 & $\mathrm{I} .22 \mathrm{I}(0.94 \mathrm{I}, \mathrm{I} .584)$ & 0.133 \\
\hline \multicolumn{5}{|l|}{ Chemotherapy } \\
\hline$\leq 0.66 \mathrm{mmol} / \mathrm{L}$ & $5.54 I(3.482,8.8 I 5)$ & $<0.001$ & $3.608(2.173,5.991)$ & $<0.001$ \\
\hline $0.67-1.04 \mathrm{mmol} / \mathrm{L}$ & I & & 1 & \\
\hline$\geq 1.05 \mathrm{mmol} / \mathrm{L}$ & $0.956(0.67 I, I .36 I)$ & 0.802 & $0.962(0.637,1.344)$ & 0.685 \\
\hline \multicolumn{5}{|l|}{ Interventional therapy } \\
\hline$\leq 0.66 \mathrm{mmol} / \mathrm{L}$ & $2.813(1.047,7.557)$ & 0.040 & $2.280(0.712,7.305)$ & 0.165 \\
\hline $0.67-1.04 \mathrm{mmol} / \mathrm{L}$ & I & & 1 & \\
\hline$\geq 1.05 \mathrm{mmol} / \mathrm{L}$ & $0.290(0.135,0.620)$ & 0.001 & $0.369(0.170,0.804)$ & 0.012 \\
\hline \multicolumn{5}{|l|}{ Untreated } \\
\hline$\leq 0.66 \mathrm{mmol} / \mathrm{L}$ & 0.0000 & 0.999 & 0.000 & 0.999 \\
\hline $0.67-1.04 \mathrm{mmol} / \mathrm{L}$ & 1 & & I & \\
\hline$\geq 1.05 \mathrm{mmol} / \mathrm{L}$ & $1.213(0.555,2.649)$ & 0.628 & $\mathrm{I} .366(0.56 \mathrm{I}, 3.324)$ & 0.492 \\
\hline
\end{tabular}

Notes: aOR was adjusted for demographic and clinical factors as age, sex, ion, ALB, HGB, WBC, sCr, comorbidities, cancer types.

by platinum. Besides, since almost $60 \%$ of magnesium is stored in bone, $20 \%$ in soft tissue, ${ }^{20}$ tumors disrupt their role in maintaining the body's magnesium balance. Hypomagnesemia frequently correlates with hypoalbuminemia because about $30 \%$ of the serum magnesium is bound to albumin. According to the fact that hypoalbuminemia is common in patients with malignancy, we compared adjusted-Mg levels in patients with or without AKI. However, there was no significant difference among the groups in our study.

AKI is common in patients with malignancy, especially patients who have hematologic tumors, multiple myeloma, and renal carcinoma. ${ }^{8}$ Compared with those without malignancy, the incidence of AKI is significantly higher in cancer patients $(12.4 \%$ vs $10.3 \%) .{ }^{9}$ In addition to normal reasons like tumor infiltration, some treatments could also result in AKI. Chemotherapy-related AKI is still a crucial and severe complication in patients with malignancy. ${ }^{21}$ Chemotherapeutic agents like cisplatin directly injure renal interstitium, renal microvasculature, and glomerulus. ${ }^{8}$ The protective effects of $\mathrm{Mg}$ to against cisplatin-induced nephrotoxicity were proposed in previous reports. ${ }^{22,23}$ Hamroun et al confirmed the benefit of magnesium administration to reduct the cisplatininduced acute renal toxicity. ${ }^{22}$ Besides, radiocontrast agents used in interventional therapy could harm the kidney by disturbing tubulodynamics and glomerular filtration, bringing out hypoperfusion and hypoxia. ${ }^{24}$ Our previous study confirmed electrolyte disturbance accompanied AKI occurrence by pointing out hyponatremia and hypokalemia were the independent risk factors for AKI $\left(\mathrm{aOR}=2.84\right.$ and 2.42) in patients with malignancy. ${ }^{9}$ Now, we focused on the effect of magnesium. In the view of the influence of treatments on AKI incidence, we carried out subgroup analysis among different therapy methods. Consistently, hypomagnesemia was still an independent risk factor for HA-AKI. There are several explanations for the responsibility of low Mg levels in HA-AKI. First, previous studies showed that low Mg levels were related to inflammation. $\mathrm{Mg}$ deficiency results in inflammation by the opening of calcium channels, upregulating proinflammatory cytokines, and activation of nuclear factor (NF)- $\kappa \mathrm{B} \cdot{ }^{25,26}$ In addition, hypomagnesemia is an important risk factor for sepsis in critically ill patients. Wang et al showed that low $\mathrm{Mg}$ level is associated with decreased monocyte cell count in patients with sepsis, $\mathrm{Mg}$ supplementation protects mice from LPS-induced septic shock. ${ }^{27}$ Salem et $\mathrm{al}^{28}$ claimed that Mg deficiency could lead to adverse outcomes of endotoxin attacks, and replacement therapy may be necessary in the case of $\mathrm{Mg}$ deficiency. Second, $\mathrm{Mg}$ promotes renal vasodilation through competing for calcium transport system, 
releasing nitric oxide (NO). Serum $\mathrm{Mg}$ disorders lead to renal hemodynamic disorders and a decreased glomerular filtration rate. Third, magnesium, served as a cofactor for ATP, plays a vital role in energy metabolism. ${ }^{29}$ Magnesium deficiency leads to abnormal energy metabolism and aggravation of hypoxia in the kidney, which gives rise to AKI. Previous studies indicated that hypomagnesemia was responsible for poor renal function in critically ill patients and AIDS patients ${ }^{30,31}$. Results from Wisit Cheungpasitporn et al study have shown that hypermagnesemia was a stronger predictor for hospital mortality and other poor outcomes including length of hospital stay and discharge to a care facility. ${ }^{32}$ These all remind us of the importance of correcting serum $\mathrm{Mg}$ disorder.

There are some limitations in this study. First, this is a single-center retrospective study. Second, data were extracted systematically from the electronic database so that we could not know the exact situation of medicine use. Nephrotoxic drugs and magnesium supplements could influence the relationship between $\mathrm{AKI}$ and $\mathrm{Mg}$ concentration. Third, many terminally ill cancer patients choose to leave the hospital voluntarily rather than die there in China so that inhospital mortality is lower than reality. Fourth, there are differences between patients who tested serum $\mathrm{Mg}$ concentration and those who did not, so a selection bias exists. In the future, we intended to pay more attention to the use of medicine and follow up automatically discharged patients.

\section{Conclusion}

Hypomagnesemia in patients with malignancy might be a risk factor for the incidence of HA-AKI. Dysmagnesemia could contribute to the development of complications and poor clinical outcomes in cancer patients.

\section{Funding}

Disclosure of grants or other funding: Shanghai Clinical Medical Center for Kidney Disease Project support by Shanghai Municipal Health Commission (No. $2017 \mathrm{Z}$ Z01015); Shanghai Municipal Hospital Frontier Technology Project supported by Shanghai ShenKang Hospital Development Center (No. SHDC12018127)

\section{Disclosure}

The authors report no conflicts of interest for this work.

\section{References}

1. Meneely KM, Sundlov JA, Gulick AM, Moran GR, Lamb AL. An open and shut case: the interaction of magnesium with MST enzymes. $J$ Am Chem Soc. 2016;138(29):9277-9293. doi:10.1021/jacs.6b05134

2. Yamanaka R, Shindo Y, Oka K. Magnesium is a key player in neuronal maturation and neuropathology. Int J Mol Sci. 2019;20:14. doi:10.3390/ijms20143439

3. Yamagami R, Bingaman JL, Frankel EA, Bevilacqua PC. Cellular conditions of weakly chelated magnesium ions strongly promote RNA stability and catalysis. Nat Commun. 2018;9(1):2149. doi:10.1038/s41467-018-04415-1

4. Lee DD, Galera-Laporta L, Bialecka-Fornal M, et al. Magnesium flux modulates ribosomes to increase bacterial survival. Cell. 2019;177 (2):352-360.e13. doi:10.1016/j.cell.2019.01.042

5. Slagelse C, Gammelager H, Iversen LH, Sørensen HT, Christiansen CF. Acute kidney injury and 1-year mortality after colorectal cancer surgery: a population-based cohort study. $B M J$ Open. 2019;9(3):e024817. doi:10.1136/bmjopen-2018-024817

6. Lam AQ, Humphreys BD. Onco-nephrology: AKI in the cancer patient. Clin J Am Soc Nephrol. 2012;7(10):1692-1700. doi:10. 2215/CJN.03140312

7. Cheng Y, Nie S, Li L, et al. Epidemiology and outcomes of acute kidney injury in hospitalized cancer patients in China. Int $J$ Cancer. 2019;144(11):2644-2650. doi:10.1002/ijc.31993

8. Rosner MH, Perazella MA. Acute kidney injury in patients with cancer. $N$ Engl J Med. 2017;376(18):1770-1781. doi:10.1056/ NEJMra1613984

9. Li Y, Chen X, Wang Y, et al. Epidemiology of acute kidney injury and associated factors among patients with malignancy: analysis of hospital inpatient database in Shanghai, China. J Onco Nephrol. 2019;3(1):39-48. doi:10.1177/2399369319830096

10. Christiansen CF, Johansen MB, Langeberg WJ, Fryzek JP, Sørensen HT. Incidence of acute kidney injury in cancer patients: a Danish population-based cohort study. Eur J Intern Med. 2011;22 (4):399-406. doi:10.1016/j.ejim.2011.05.005

11. Lameire N, Van Biesen W, Vanholder R. Electrolyte disturbances and acute kidney injury in patients with cancer. Semin Nephrol. 2010;30 (6):534-547. doi:10.1016/j.semnephrol.2010.09.002

12. Rosner MH, Capasso G, Perazella MA. Acute kidney injury and electrolyte disorders in the critically ill patient with cancer. Curr Opin Crit Care. 2017;23(6):475-483. doi:10.1097/MCC.0000000000000450

13. Group, K. D. I. G. O. A. K. I. W.. KDIGO clinical practice guideline for acute kidney injury. Kidney Int Suppl. 2012;2(1):1-138.

14. Xu X, Nie S, Liu Z, et al. Epidemiology and Clinical Correlates of AKI in Chinese Hospitalized adults. Clin J Am Soc Nephrol. 2015;10 (9):1510-1518. doi:10.2215/CJN.02140215

15. Pakfetrat M, Roozbeh Shahroodi J, Malekmakan L, Zare N, Hashemi Nasab M, Hossein Nikoo M. Is there an association between intradialytic hypotension and serum magnesium changes? Hemodial Int. 2010;14(4):492-497. doi:10.1111/j.1542-4758.2010.00477.x

16. Houillier P. Mechanisms and regulation of renal magnesium transport. Annu Rev Physiol. 2014;76:411-430. doi:10.1146/annurevphysiol-021113-170336

17. Huang CL, Kuo E. Mechanism of hypokalemia in magnesium deficiency. J Am Soc Nephrol. 2007;18(10):2649-2652. doi:10.1681/ ASN.2007070792

18. Vadiveloo T, Donnan PT, Leese GP. A population-based study of the epidemiology of chronic hypoparathyroidism. J Bone Mineral Res. 2018;33(3):478-485. doi:10.1002/jbmr.3329

19. Liamis G, Filippatos TD, Elisaf MS. Electrolyte disorders associated with the use of anticancer drugs. Eur J Pharmacol. 2016;777:78-87. doi:10.1016/j.ejphar.2016.02.064

20. Elin RJ. Assessment of magnesium status. Clin Chem. 1987;33 (11):1965-1970. doi:10.1093/clinchem/33.11.1965 
21. Perazella MA. Onco-nephrology: renal toxicities of chemotherapeutic agents. Clin J Am Soc Nephrol. 2012;7(10):1713-1721. doi:10.2215/ CJN.02780312

22. Hamroun A, Lenain R, Bigna JJ, et al. Prevention of cisplatin-induced acute kidney injury: a systematic review and meta-analysis. Drugs. 2019;79(14):1567-1582.

23. Holditch SJ, Brown CN, Lombardi AM, Nguyen KN, Edelstein CL. Recent advances in models, mechanisms, biomarkers, and interventions in cisplatin-induced acute kidney injury. Int J Mol Sci. 2019;20 (12):12. doi:10.3390/ijms20123011

24. Fähling M, Seeliger E, Patzak A, Persson PB. Understanding and preventing contrast-induced acute kidney injury. Nat Rev Nephrol. 2017;13(3):169-180. doi:10.1038/nrneph.2016.196

25. Shahi A, Aslani S, Ataollahi M, Mahmoudi M. The role of magnesium in different inflammatory diseases. Inflammopharmacology. 2019;27(4):649-661. doi:10.1007/s10787-019-00603-7

26. Tam M, Gómez S, González-Gross M, Marcos A. Possible roles of magnesium on the immune system. Eur J Clin Nutr. 2003;57 (10):1193-1197. doi:10.1038/sj.ejcn.1601689

27. Wang $\mathrm{D}$, Zheng $\mathrm{J}, \mathrm{Hu} \mathrm{Q}$, et al. Magnesium protects against sepsis by blocking gasdermin D N-terminal-induced pyroptosis. Cell Death Differ. 2020;27(2):466-481. doi:10.1038/s41418-019-0366-х
28. Salem M, Kasinski N, Munoz R, Chernow B. Progressive magnesium deficiency increases mortality from endotoxin challenge: protective effects of acute magnesium replacement therapy. Crit Care Med. 1995;23(1):108-118. doi:10.1097/00003246-199501000-00019

29. Cowan JA. Structural and catalytic chemistry of magnesium-dependent enzymes. Biometals. 2002;15(3):225-235. doi:10.1023/A:1016022730 880

30. Alves SC, Tomasi CD, Constantino L, et al. Hypomagnesemia as a risk factor for the non-recovery of the renal function in critically ill patients with acute kidney injury. Nephrol Dialysis Transplant. 2013;28(4):910-916. doi:10.1093/ndt/gfs268

31. Santos MS, Seguro AC, Andrade L. Hypomagnesemia is a risk factor for nonrecovery of renal function and mortality in AIDS patients with acute kidney injury. Braz J Med Biol Res. 2010;43(3):316-323. doi:10.1590/S0100-879X2010007500002

32. Cheungpasitporn W, Thongprayoon C, Qian Q. Dysmagnesemia in hospitalized patients: prevalence and prognostic importance. Mayo Clin proc. 2015;90(8):1001-1010. doi:10.1016/j.mayocp.2015. 04.023

\section{Publish your work in this journal}

Cancer Management and Research is an international, peer-reviewed open access journal focusing on cancer research and the optimal use of preventative and integrated treatment interventions to achieve improved outcomes, enhanced survival and quality of life for the cancer patient.
The manuscript management system is completely online and includes a very quick and fair peer-review system, which is all easy to use. Visit http://www.dovepress.com/testimonials.php to read real quotes from published authors. 